\title{
O sobre-humano nos imaginários cinematográficos bem-sucedidos ${ }^{1}$
}

\section{The superhuman in the successful cinematic imaginaries}

Sílvio Antonio Luiz Anaz ${ }^{2}$

Resumo: Um dos fatores que explica o sucesso global de algumas produções cinematográficas é a capacidade que os imaginários que emergem delas têm em seduzir audiências e penetrar em diferentes culturas. Este artigo analisa um conjunto de narrativas cinematográficas para revelar parte dos elementos simbólicos e dos sentidos dominantes no imaginário que emergem dos filmes preferidos pela audiência. Para fazer isso, parte da contextualização dos mercados, do levantamento dos gêneros e temas de maior audiência entre 2001 e 2015 e dos conceitos sobre imaginário e mito em Gilbert Durand e Mircea Eliade. Os resultados apontam para a popularidade de uma combinação dos gêneros de aventura, ação, ficção científica e fantasia, que têm em comum o arquétipo do sobre-humano no núcleo das narrativas.

Palavras-chave: cinema; imaginário; mitocrítica; sobre-humano; Hollywood.

Abstract: One element that explains the global success of some movies is the capacity that their imaginaries have in seducing the audiences in different cultures. This paper analyzes a group of cinematic narratives to reveal part of the symbolic elements and main meanings in the imaginaries that emerges from the most popular movies from 2001 to 2015. In order to do that the analysis is based uses market data, a research about the most popular themes and genres in

1 Esta pesquisa conta com o apoio da Fundação de Amparo à Pesquisa do Estado de São Paulo - Fapesp e da Capes (Processo n 2014/13330-1). As opiniões, hipóteses e conclusões ou recomendações expressas neste material são de responsabilidade do autor e não necessariamente refletem a visão da Fapesp e da Capes.

2 Universidade de São Paulo. São Paulo, SP, Brasil. E-mail: silvioanaz@hotmail.com 
the period and the concepts about the imaginary and myths from Gilbert Durand and Mircea Eliade. The results show the popularity of a combination of adventure, action, science fiction and fantasy genres that has in common the superhuman archetype in the core of the narratives.

Keywords: cinema; imaginary; myth criticism; superhuman; Hollywood. 


\section{Introdução}

A investigação apresentada neste artigo parte do levantamento dos gêneros e temas predominantes no conjunto de películas mais bem-sucedidas comercialmente entre 2001 e 2015 para desenvolver um estudo sobre aspectos dos imaginários compartilhados pelos filmes mais populares desse começo de milênio.

Entendido o imaginário na concepção durandiana - conjunto dinâmico de elementos simbólicos produzidos em um trajeto antropológico (DURAND, 2002) que se articulam, gerando sentidos e funções simbólicas materializados em narrativas -, os imaginários cinematográficos são analisados neste estudo por meio da metodologia da mitocrítica proposta por Durand. Busca-se mapear o imaginário que emerge do conjunto de obras cinematográficas que tiveram a preferência do público.

A importância de se compreender o funcionamento dos imaginários é destacada por Morin, para quem os criadores dos filmes projetam no ar as estruturas do imaginário, estando nossa psique nas imagens dos filmes e vice-versa:

O cinema nos faz entender não apenas teatro, poesia e música, mas também o teatro interno de nossa mente: sonhos, imagens imaginadas, representações: este pequeno cinema que temos em nossa cabeça (MORIN, 2005, p. 203).

Como veremos a seguir, os filmes com gêneros e temas que predominam nesse pequeno cinema que temos em nossa cabeça nesse começo de milênio foram majoritariamente criados na lógica de produção de Hollywood.

\section{Gêneros bem-sucedidos: o soft power de Hollywood}

Em 2015, os seis principais estúdios cinematográficos (Universal, Disney, Fox, Warner, Sony/Columbia e Paramount) arrecadaram cerca de 
68\% da bilheteria mundial. ${ }^{3}$ Desse montante, cerca de dois terços vieram de fora do mercado norte-americano (EUA e Canadá).

Tal resultado mostra a elevada capacidade de penetração dos títulos produzidos nos Estados Unidos em diferentes culturas. Em 2015, a China, apesar de todas as restrições protecionistas e censórias que impõe à exibição de filmes estrangeiros, contribuiu com quase um quarto do faturamento internacional dos filmes produzidos nos Estados Unidos. No Brasil, as produções norte-americanas ficaram com $84 \%$ do arrecadado nas bilheterias ${ }^{4}$ e na França, no mesmo ano, os filmes norte-americano ficaram com $52 \%$ das bilheterias. ${ }^{5}$

O domínio do mercado cinematográfico mundial - que ocorre desde os anos 1920, quando os estúdios dos EUA superaram os europeus, principalmente os franceses - surge como fruto da articulação entre estratégias de negócios e capacidade de percepção dos gostos do público (BAKKER, 2004 apud SEDGWICK e POKORNY, 2004).

Ao longo das décadas de 1910 e 1920, a indústria cinematográfica norte-americana começa a produzir filmes com elevados orçamentos - o que leva à escalada nos custos de produção, que a indústria europeia não arriscou seguir, e também à criação de um ecossistema (cadeia produtiva) completo e altamente profissionalizado para a produção de filmes -, lança o formato longa-metragem, passa a desenvolver narrativas ficcionais, baseadas em sucessos literários, dramaturgias e narrativas míticas, e os principais estúdios assumem a distribuição dos próprios filmes nos mercados nacional e internacional, com a criação de empresas distribuidoras subsidiárias e redes próprias de salas de exibição (SEDGWICK e POKORNY, 2004). Além disso, os estúdios adotam um sistema

3 Dados disponíveis no Rentrak e nos balanços anuais mostram os seguintes resultados em 2015: Universal Pictures - US\$ 6,9 bilhões; Disney - US\$ 5,85 bilhões; 21 st Century Fox - US\$ 4,033 bilhões; Warner - US\$ 3,421 bilhões; Paramount - US\$2,885 bilhões; e Sony/Columbia - US\$ 2,838 bilhões.

4 Dados da Ancine - Observatório do Cinema e do Audiovisual (OCA) e do Box Office Mojo.

5 Dados disponíveis no documento Results 2015: Films, television programs, production, distribution, exhibition, exports, video, new media do Centre national du cinéma et de l'image animée. Disponível em: http://www.cnc.fr/web/en/publications/-/ressources/9459748. Acesso em: 3 out. 2016. 
de produção inspirado na ideia de linha de montagem ${ }^{6}$ da indústria automobilística e o mercado interno norte-americano se consolida como o maior do planeta.

Em um amplo recenseamento sobre a cultura mainstream no mundo, Martel constrói a hipótese de que, além do poder econômico dos estúdios, há uma combinação de fatores atuais - muitos deles fora da lógica do mercado - que mantém o domínio das indústrias de entretenimento sediadas nos Estados Unidos, especialmente a cinematográfica:

Elas [as explicações para o domínio cultural norte-americano] têm a ver com causas múltiplas, aqui evocadas em pinceladas gerais: na origem, um cruzamento original entre a pesquisa estimulada nas universidades, financiamentos públicos muito descentralizados, uma contracultura valorizada em numerosos focos alternativos, a energia proveniente da mobilidade e da ideia de ascensão social, tão fortemente enraizada na sociedade americana, a confiança depositada nos artistas singulares e a vivacidade excepcional das comunidades étnicas, graças ao modelo original de integração e defesa de uma "diversidade cultural" à americana. Formação, inovação, riscos assumidos, criatividade, ousadia: é nas universidades, nas comunidades e no setor não lucrativo que essas tendências se manifestam nos Estados Unidos, fora do mercado e de maneira muito descentralizada (MARTEL, 2012, p. 448).

Além do poderio econômico, as principais corporações (Comcast, Viacom, Time Warner, $21^{\text {st }}$ Century Fox e The Walt Disney Company) que comandam a indústria cinematográfica têm no poder de sedução das estéticas e dos conteúdos dos filmes que produzem e distribuem um fator decisivo para o seu elevado grau de penetração e aceitação nos mercados de vários países. Cria-se, assim, um círculo virtuoso em que o sucesso econômico alimenta o sucesso estético e de conteúdo e vice-versa. O alto grau de sedução gera elevados faturamentos, com o domínio de $68 \%$ da bilheteria global, que, por sua vez, geram sofisticados clusters, ecossistemas e cadeia produtiva para a indústria cinematográfica

6 A ideia de adotar o mesmo sistema da indústria automobilística para a produção cinematográfica surge na Paramount Pictures, fundada em 1912 pelo imigrante húngaro Adolph Zukor em sociedade com os irmãos Daniel e Charles Frohman. 
norte-americana, o que estimula e sustenta vários dos fatores apontados por Martel.

Também é preciso ressaltar, em relação ao sucesso dos produtos dos grandes estúdios no período aqui investigado (2001-2015), o relevante papel que têm as estratégias de marketing ${ }^{7}$ e o uso de efeitos visuais, que, graças ao estado da arte da tecnologia de imagens geradas por computador (CGI, na sigla em inglês), ampliaram as possibilidades estéticas e narrativas dos criadores.

Ponderados esses fatores, este estudo se volta para os fatores qualitativos que impactam na estética e no conteúdo de um filme, como roteiro, direção, elenco, equipes e recursos técnicos, entre outros, e para a complexa combinação entre eles. A investigação foca no imaginário construído pelos filmes, aspecto mais geral em que o roteiro e as imagens arquetípicas exercem um papel primordial. Pois, como afirma Morin (2005, p. 204): “o cinema nos permite ver o processo de penetração do homem no mundo e o inseparável processo de penetração do mundo no homem".

A partir da hipótese de que os filmes de maior sucesso compartilham algumas características no âmbito do imaginário que operam como conectores na identificação cultural que as audiências globais estabelecem com eles, esta investigação busca mapear e descrever esse imaginário a partir da identificação dos principais elementos simbólicos partilhados nos filmes e da interpretação de seus sentidos e compreender uma parte do inconsciente antropológico do mundo contemporâneo.

Compor um retrato do imaginário mais bem-sucedido no cinema internacional entre 2001 e 2015 começa pelo levantamento dos gêneros ${ }^{8}$ e temas mais frequentes nos filmes que foram sucesso de público nesse período. Com base nas cinco maiores bilheterias mundiais registradas

7 A chamada "Era dos Blockbusters", cujo marco inicial é a campanha de lançamento do filme Tubarão (Steven Spielberg, 1975), tem, entre suas características principais, a adoção de campanhas intensivas de marketing, com divulgação abundante e muitas vezes inovadora e planos de distribuição que levam à ocupação massiva das salas de exibição.

8 Categorias classificativas que permitem estabelecer relações de semelhança ou identidade entre as diversas obras, baseadas em critérios narrativos (o que se conta e o modo como se conta) e técnicos (NOGUEIRA, 2010, p. 3-6). 
anualmente entre 2001 e 2015,9 é possível observar que os principais gêneros ${ }^{10}$ presentes nas produções mais bem-sucedidas no começo deste milênio são: aventura (82\%), ação (57\%), fantasia (32\%), animação (20\%) e ficção científica (18\%).

Tabela 1. Filmes com maiores bilheterias mundiais - 2001 a 2015.

\begin{tabular}{|c|c|c|c|c|c|}
\hline Ano & $\begin{array}{l}\text { Maior } \\
\text { bilheteria }\end{array}$ & $\begin{array}{l}\text { Segunda maior } \\
\text { bilheteria }\end{array}$ & $\begin{array}{l}\text { Terceira maior } \\
\text { bilheteria }\end{array}$ & $\begin{array}{l}\text { Quarta maior } \\
\text { bilheteria }\end{array}$ & $\begin{array}{l}\text { Quinta maior } \\
\text { bilheteria }\end{array}$ \\
\hline 2015 & $\begin{array}{l}\text { Star Wars: O } \\
\text { Despertar da } \\
\text { Força }\end{array}$ & Jurassic World & $\begin{array}{l}\text { Velozes e } \\
\text { Furiosos } 7\end{array}$ & $\begin{array}{l}\text { Vingadores: } \\
\text { Era de Ultron }\end{array}$ & Minions \\
\hline 2014 & $\begin{array}{l}\text { Transfor- } \\
\text { mers: Era da } \\
\text { Extinção }\end{array}$ & $\begin{array}{l}\text { O Hobbit: A } \\
\text { Batalha dos } \\
\text { Cinco Exércitos }\end{array}$ & $\begin{array}{l}\text { Guardiões da } \\
\text { Galáxia }\end{array}$ & Malévola & $\begin{array}{l}\text { Jogos Vorazes: } \\
\text { A Esperança } \\
\text { (1) }\end{array}$ \\
\hline 2013 & $\begin{array}{l}\text { Frozen: Uma } \\
\text { Aventura } \\
\text { Congelante }\end{array}$ & $\begin{array}{l}\text { Homem de } \\
\text { Ferro } 3\end{array}$ & $\begin{array}{l}\text { Meu Malvado } \\
\text { Favorito } 2\end{array}$ & $\begin{array}{l}\text { O Hobbit: A } \\
\text { Desolação de } \\
\text { Smaug }\end{array}$ & $\begin{array}{l}\text { Jogos Vorazes: } \\
\text { Em Chamas }\end{array}$ \\
\hline 2012 & Os Vingadores & $\begin{array}{l}\text { 007: Operação } \\
\text { Skyfall }\end{array}$ & $\begin{array}{l}\text { Batman: } \mathrm{O} \\
\text { Cavaleiro das } \\
\text { Trevas Ressurge }\end{array}$ & $\begin{array}{l}\text { O Hobbit: } \\
\text { Uma Jornada } \\
\text { Inesperada }\end{array}$ & $\begin{array}{l}\text { A Era do } \\
\text { Gelo } 4\end{array}$ \\
\hline 2011 & $\begin{array}{l}\text { Harry Potter e } \\
\text { as Relíquias da } \\
\text { Morte (2) }\end{array}$ & $\begin{array}{l}\text { Transformers: } \\
\text { O Lado Oculto } \\
\text { da Lua }\end{array}$ & $\begin{array}{l}\text { Piratas do } \\
\text { Caribe: Nave- } \\
\text { gando em Águas } \\
\text { Misteriosas }\end{array}$ & $\begin{array}{l}\text { A Saga } \\
\text { Crepúsculo: } \\
\text { Amanhecer (1) }\end{array}$ & $\begin{array}{l}\text { Missão Impos- } \\
\text { sível: Protocolo } \\
\text { Fantasma }\end{array}$ \\
\hline 2010 & Toy Story 3 & $\begin{array}{l}\text { Alice no País } \\
\text { das Maravilhas }\end{array}$ & $\begin{array}{l}\text { Harry Potter e } \\
\text { as Relíquias da } \\
\text { Morte }\end{array}$ & A Origem & $\begin{array}{l}\text { Shrek para } \\
\text { Sempre }\end{array}$ \\
\hline 2009 & Avatar & $\begin{array}{l}\text { Harry Potter e } \\
\text { o Enigma do } \\
\text { Príncipe }\end{array}$ & $\begin{array}{l}\text { A Era do } \\
\text { Gelo } 3\end{array}$ & $\begin{array}{l}\text { Transformers: A } \\
\text { Vingança dos } \\
\text { Derrotados }\end{array}$ & 2012 \\
\hline 2008 & $\begin{array}{l}\text { Batman - O } \\
\text { Cavaleiro das } \\
\text { Trevas }\end{array}$ & $\begin{array}{l}\text { Indiana Jones } \\
\text { e o Reino da } \\
\text { Caveira de } \\
\text { Cristal }\end{array}$ & Kung Fu Panda & Hancock & Mamma Mia! \\
\hline 2007 & $\begin{array}{l}\text { Piratas do } \\
\text { Caribe: No Fim } \\
\text { do Mundo }\end{array}$ & $\begin{array}{l}\text { Harry Potter } \\
\text { e a Ordem da } \\
\text { Fênix }\end{array}$ & $\begin{array}{l}\text { Homem-Ara- } \\
\text { nha } 3\end{array}$ & Shrek Terceiro & Transformers \\
\hline
\end{tabular}

9 Segundo dados do Box Office Mojo, disponível em: <http://www.boxofficemojo.com/yearly/?vi ew2=worldwide\&view=releasedate\&p=.htm>. Acesso em: 10 de outubro 2016.

10 Segundo a classificação do International Movie Data Base (IMDb) (http://www.imdb.com/>), cada filme é classificado em até três gêneros. 
Tabela 1 (continuação)

\begin{tabular}{|c|c|c|c|c|c|}
\hline Ano & $\begin{array}{l}\text { Maior } \\
\text { bilheteria }\end{array}$ & $\begin{array}{l}\text { Segunda maior } \\
\text { bilheteria }\end{array}$ & $\begin{array}{l}\text { Terceira maior } \\
\text { bilheteria }\end{array}$ & $\begin{array}{l}\text { Quarta maior } \\
\text { bilheteria }\end{array}$ & $\begin{array}{l}\text { Quinta maior } \\
\text { bilheteria }\end{array}$ \\
\hline 2006 & $\begin{array}{l}\text { Piratas do } \\
\text { Caribe: O Baú } \\
\text { da Morte }\end{array}$ & $\begin{array}{l}\text { Código da } \\
\text { Vinci }\end{array}$ & $\begin{array}{l}\text { A Era do } \\
\text { Gelo } 2\end{array}$ & $\begin{array}{l}007 \text { Cassino } \\
\text { Royale }\end{array}$ & $\begin{array}{l}\text { Uma Noite no } \\
\text { Museu }\end{array}$ \\
\hline 2005 & $\begin{array}{l}\text { Harry Potter e o } \\
\text { Cálice de Fogo }\end{array}$ & $\begin{array}{l}\text { Star Wars: A } \\
\text { Vingança dos } \\
\text { Sith }\end{array}$ & $\begin{array}{l}\text { As Crônicas de } \\
\text { Nárnia }\end{array}$ & $\begin{array}{l}\text { Guerra dos } \\
\text { Mundos }\end{array}$ & King Kong \\
\hline 2004 & Shrek 2 & $\begin{array}{l}\text { Harry Potter e } \\
\text { o Prisioneiro de } \\
\text { Azkaban }\end{array}$ & $\begin{array}{l}\text { Homem-Ara- } \\
\text { nha } 2\end{array}$ & Os Incríveis & $\begin{array}{l}\text { A Paixão de } \\
\text { Cristo }\end{array}$ \\
\hline 2003 & $\begin{array}{l}\text { O Senhor dos } \\
\text { Anéis: O Retor- } \\
\text { no do Rei }\end{array}$ & $\begin{array}{l}\text { Procurando } \\
\text { Nemo }\end{array}$ & $\begin{array}{l}\text { Matrix: } \\
\text { Reloaded }\end{array}$ & $\begin{array}{l}\text { Piratas do } \\
\text { Caribe: A Mal- } \\
\text { dição do Pérola } \\
\text { Negra }\end{array}$ & Todo Poderoso \\
\hline 2002 & $\begin{array}{l}\text { O Senhor dos } \\
\text { Anéis: As Duas } \\
\text { Torres }\end{array}$ & $\begin{array}{l}\text { Harry Potter } \\
\text { e a Câmara } \\
\text { Secreta }\end{array}$ & Homem-Aranha & $\begin{array}{l}\text { Star Wars: } \\
\text { Ataque dos } \\
\text { Clones }\end{array}$ & $\begin{array}{l}\text { Homem de } \\
\text { Preto } 2\end{array}$ \\
\hline 2001 & $\begin{array}{l}\text { Harry Potter e a } \\
\text { Pedra Filosofal }\end{array}$ & $\begin{array}{l}\text { O Senhor dos } \\
\text { Anéis: A Socie- } \\
\text { dade do Anel }\end{array}$ & Monstros S.A. & Shrek & $\begin{array}{l}\text { Onze Homens e } \\
\text { Um Segredo }\end{array}$ \\
\hline
\end{tabular}

Fonte: Box Office Mojo.

Tabela 2. Filmes com maiores bilheterias no Brasil - 2011 a 2015.

\begin{tabular}{|c|c|c|c|c|c|}
\hline Ano & $\begin{array}{l}\text { Maior } \\
\text { bilheteria }\end{array}$ & $\begin{array}{l}\text { Segunda maior } \\
\text { bilheteria }\end{array}$ & $\begin{array}{l}\text { Terceira maior } \\
\text { bilheteria }\end{array}$ & $\begin{array}{l}\text { Quarta maior } \\
\text { bilheteria }\end{array}$ & $\begin{array}{l}\text { Quinta maior } \\
\text { bilheteria }\end{array}$ \\
\hline 2015 & $\begin{array}{l}\text { Vingadores: A } \\
\text { Era de Ultron }\end{array}$ & $\begin{array}{l}\text { Velozes e } \\
\text { Furiosos } 7\end{array}$ & Minions & $\begin{array}{l}\text { Cinquenta } \\
\text { Tons de Cinza }\end{array}$ & Jurassic World \\
\hline 2014 & $\begin{array}{l}\text { A Culpa é das } \\
\text { Estrelas }\end{array}$ & Malévola & Rio 2 & $\begin{array}{l}\text { X-Men: Dias } \\
\text { de um Futuro } \\
\text { Esquecido }\end{array}$ & Noé \\
\hline 2013 & $\begin{array}{l}\text { Homem de } \\
\text { Ferro } 3\end{array}$ & $\begin{array}{l}\text { Meu Malvado } \\
\text { Favorito } 2\end{array}$ & $\begin{array}{l}\text { Thor 2: O } \\
\text { Mundo } \\
\text { Sombrio }\end{array}$ & $\begin{array}{l}\text { Minha Mãe é } \\
\text { uma Peça }\end{array}$ & $\begin{array}{l}\text { Velozes e } \\
\text { Furiosos } 6\end{array}$ \\
\hline 2012 & Os Vingadores & $\begin{array}{l}\text { A Saga } \\
\text { Crepúsculo: } \\
\text { Amanhecer (2) }\end{array}$ & $\begin{array}{l}\text { A Era do } \\
\text { Gelo } 4\end{array}$ & $\begin{array}{l}\text { Madagascar 3: } \\
\text { Os Procurados }\end{array}$ & $\begin{array}{l}\text { Alvim e os } \\
\text { Esquilos }\end{array}$ \\
\hline 2011 & $\begin{array}{l}\text { A Saga } \\
\text { Crepúsculo: } \\
\text { Amanhecer (1) }\end{array}$ & Rio & $\begin{array}{l}\text { Harry Potter e } \\
\text { as Relíquias da } \\
\text { Morte (2) }\end{array}$ & Os Smurfs & Gato de Botas \\
\hline
\end{tabular}

Fonte: Ancine. 
Ao se recortar os resultados das bilheterias entre 2011 e 2015, observa-se que se manteve a tendência registrada na década anterior de predomínio da combinação dos gêneros aventura e ação tanto no cenário externo (Tabela 1) como no Brasil (Tabela 2). Na comparação desses dois cenários, as únicas diferenças mais significativas estão na maior popularidade que os gêneros comédia e animação têm no Brasil em relação à média internacional.

Tabela 3: Gêneros mais assistidos nos cinemas (2011-2015).

\begin{tabular}{lll}
\hline Gênero & Internacional & Brasil \\
\hline Aventura & $84 \%$ & $76 \%$ \\
Ação & $64 \%$ & $48 \%$ \\
Ficção científica & $32 \%$ & $20 \%$ \\
Fantasia & $28 \%$ & $24 \%$ \\
Thriller & $24 \%$ & $16 \%$ \\
Animação & $16 \%$ & $36 \%$ \\
Comédia & $12 \%$ & $32 \%$ \\
Drama & $12 \%$ & $20 \%$ \\
Família & $4 \%$ & $4 \%$ \\
Crime & $4 \%$ & $8 \%$ \\
Mistério & $4 \%$ & $0 \%$ \\
Romance & $0 \%$ & $8 \%$ \\
\hline
\end{tabular}

Fonte: IMDb.

Na popular combinação dos gêneros de aventura e ação, narram-se jornadas caracterizadas por protagonistas em busca de conquistas (recuperar alguém ou algo) e explorações (enfrentar o desconhecido), com o predomínio das sequências de lutas, fugas, perseguições e catástrofes. Em geral, nos filmes desses gêneros de maior sucesso entre 2011 e 2015, as sequências de lutas, fugas, perseguições e catástrofes ocupam de $20 \%$ a 30\% da duração total da narrativa. Tais cenas são fundamentais para o 
efeito catártico ${ }^{11}$ do filme, catarse que também se dá pela "resolução das rupturas no status quo" (O’BRIEN, 2012, p. 3).

O formato das narrativas cinematográficas de ação foi modelado, em grande parte, pela estética e dinâmica dos filmes produzidos em Hong Kong a partir dos anos 1960 e que exerceram grande influência nas produções de Hollywood da década de 1970, principalmente por seu sucesso transnacional. Para Morris, as produções da indústria cinematográfica na então colônia britânica na China - notadamente aquelas em que as cenas de artes marciais prevalecem - têm um papel fundamental na formatação do gênero de ação na indústria cinematográfica dos Estados Unidos e de diversos países (MORRIS, 2006, p. 1).

O que se observa neste começo de milênio é que os filmes de ação e aventura bem-sucedidos incluem geralmente elementos de ficção científica e/ou fantasia.

Nessa matriz que mistura elementos de aventura, ação, ficção científica e fantasia, destacam-se os temas dos super-heróis, oriundos das histórias em quadrinhos (Os Vingadores, Homem de Ferro, Batman, Guardiões da Galáxia) e dos universos sobrenaturais baseados em obras literárias (Harry Potter, Crepúsculo, O Hobbit). Eles representam cerca de 40\% dos maiores sucessos entre 2011 e 2015 tanto no cenário internacional como no brasileiro. Isto é, histórias e personagens consagrados em outras linguagens repetem o sucesso em suas versões cinematográficas.

Joshi e Mao (2012), em estudo sobre as adaptações literárias para o cinema, mostram que um filme tem suas chances de sucesso aumentadas (assim como a consequente produção de sequências) quando é adaptação de um livro e reproduz com fidelidade o conteúdo da obra.

Outro ponto de destaque é o sucesso das franquias no período (Os Vingadores, O Hobbit, Harry Potter etc.).

Os ciclos de predominância estética e temática são explicados por uma dinâmica que envolve negócios e aspectos do gosto popular. Os sucessos de bilheteria têm regularmente engendrado tendências cujo

11 A catarse, segundo Aristóteles (2004), é o processo de purgação ou eliminação das paixões que se produz no espectador quando, no teatro, ele assiste à representação de uma tragédia. 
resultado são filmes com histórias e características estéticas similares, formando linhagens sujeitas a ciclos de vida: "Filmes altamente bem-sucedidos nas bilheterias emitem sinais das preferências da audiência para os estúdios que os produziram e também para os rivais" (SEDGWICK e POKORNY, 2004, p. 304). Trata-se de um componente importante na fórmula de minimização dos riscos de investimentos.

As linhagens que predominam no gosto popular no início deste milênio são as dos filmes de aventura e ação, que desenvolvem temas de ficção científica e/ou fantásticos. Identificar os elementos simbólicos redundantes nos filmes preferidos da audiência pode revelar o que está no núcleo do imaginário que tem sido compartilhado com sucesso pelo cinema mainstream. São esses elementos que se busca mapear a seguir.

\section{O sobre-humano no imaginário dos filmes de sucesso}

Apoiado em uma perspectiva antropológica, inspirado pelos trabalhos de Gastón Bachelard e Carl Jung e a partir de um amplo estudo da produção simbólica em diferentes sociedades e momentos históricos, Gilbert Durand (1921-2012) desenvolve sua teoria geral do imaginário, na qual as imagens arquetípicas e as narrativas míticas ocupam um papel central. Um dos frutos metodológicos de sua teoria é a mitocrítica, que Durand (1985) estabelece como um método que parte do levantamento dos temas, motivos, situações e combinatórias de situações, personagens e cenários mais redundantes nas narrativas para identificar os mitemas (menor elemento significativo de um mito) presentes no discurso de forma patente ou latente. A partir dos mitemas e dos significados ou lições que trazem, é possível estabelecer correlações entre os sentidos encontrados nas narrativas e os mitos de uma época ou cultura determinada que sirva de referência.

A mitocrítica se insere na hipótese durandiana de que os mitos são modelos matriciais de todo discurso. Os mitos circulam, segundo Durand (2012, p. 131), como forças dominantes ou contraculturais nas sociedades ao longo da história. As produções culturais seriam, assim, orientadas e desorientadas por mitos fundadores. 
O mapeamento do grupo de filmes campeões de bilheteria, ${ }^{12}$ que permite identificar as características das preferências do público, conforme visto na primeira parte deste estudo (gêneros de aventura e ação combinados com a ficção científica e/ou a fantasia), leva à identificação dos elementos simbólicos mais redundantes partilhados por eles (Figura 1).

Figura 1. Mapa dos principais elementos simbólicos e mitemas (2011-2015).

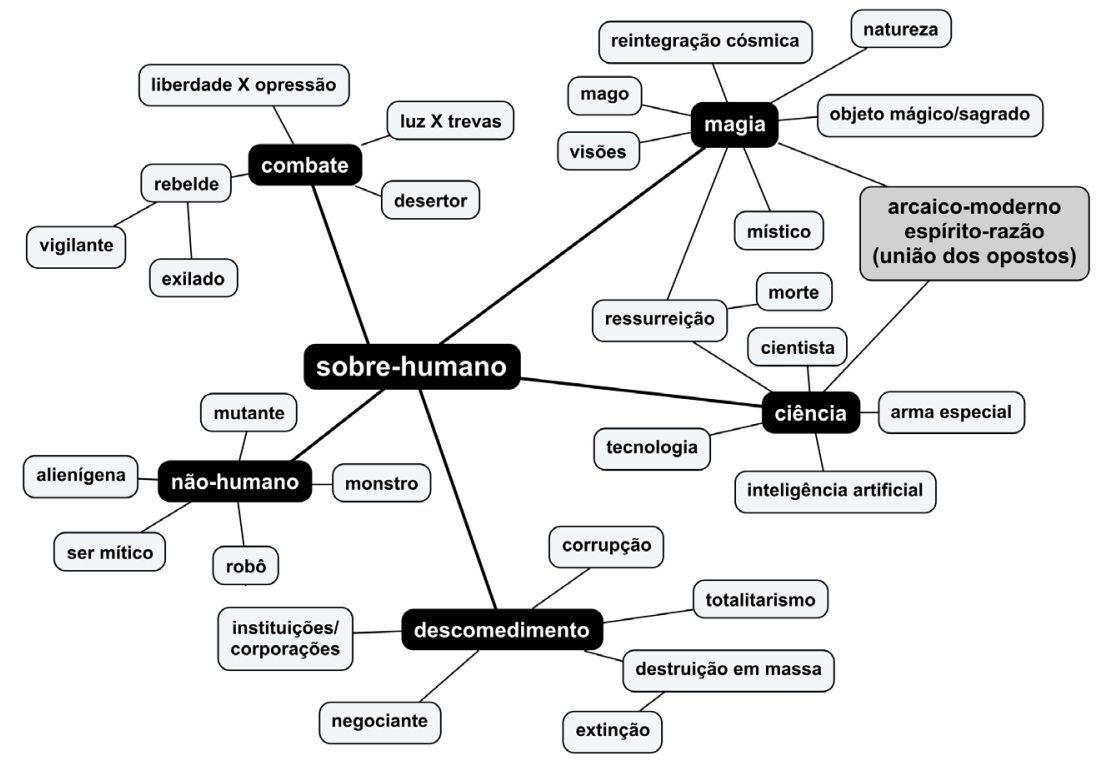

Fonte: elaboração própria.

12 A mitocrítica foi aplicada aos filmes: Star Wars: O Despertar da Força (J. J. Abrams, 2015), Vingadores: Era de Ultron (Joss Whedon, 2015), Transformers: Era da Extinção (Michael Bay, 2014), O Hobbit: A Batalha dos Cinco Exércitos (Peter Jackson, 2014), Guardiões da Galáxia (James Gunn, 2014), Homem de Ferro 3 (Shane Black, 2013), O Hobbit: A Desolação de Smaug (Peter Jackson, 2013), Os Vingadores (Joss Whedon, 2012), Batman: O Cavaleiro das Trevas Ressurge (Christopher Nolan, 2012), O Hobbit: Uma Jomada Inesperada (Peter Jackson, 2012), Harry Potter e as Relíquias da Morte - Parte 2 (David Yates, 2011), Transformers: O Lado Oculto da Lua (Michael Bay, 2011), Piratas do Caribe: Navegando em Águas Misteriosas (Rob Marshall, 2011) e A Saga Crepúsculo: Amanhecer - Parte 1 (Bill Condon, 2011). Essas narrativas correspondem a cerca de 60\% das maiores bilheterias globais entre 2011 e 2015 e todas têm em comum serem dos gêneros de aventura e ação em combinação com a ficção científica e/ou a fantasia e terem o tema do sobre-humano no núcleo de seus imaginários. 
O mapeamento (Figura 1) mostra os mais frequentes elementos simbólicos presentes nos filmes de maior sucesso entre 2011 e 2015 nos gêneros aventura, ação, ficção científica e fantasia e suas convergências, por similaridade de sentidos e funções, em cinco mitemas: magia, ciência, não humano, combate e descomedimento. Esses mitemas, por sua vez, têm como elemento simbólico em comum a imagem arquetípica do "sobre-humano", que está presente em todos os filmes analisados e se torna central no imaginário que emerge do conjunto das narrativas.

Um outro aspecto é que a combinação dos mitemas identificados caracteriza os principais personagens sobre-humanos que protagonizam os filmes analisados (Figura 2):

Figura 2. Mapa dos temas associados aos principais personagens sobre-humanos.

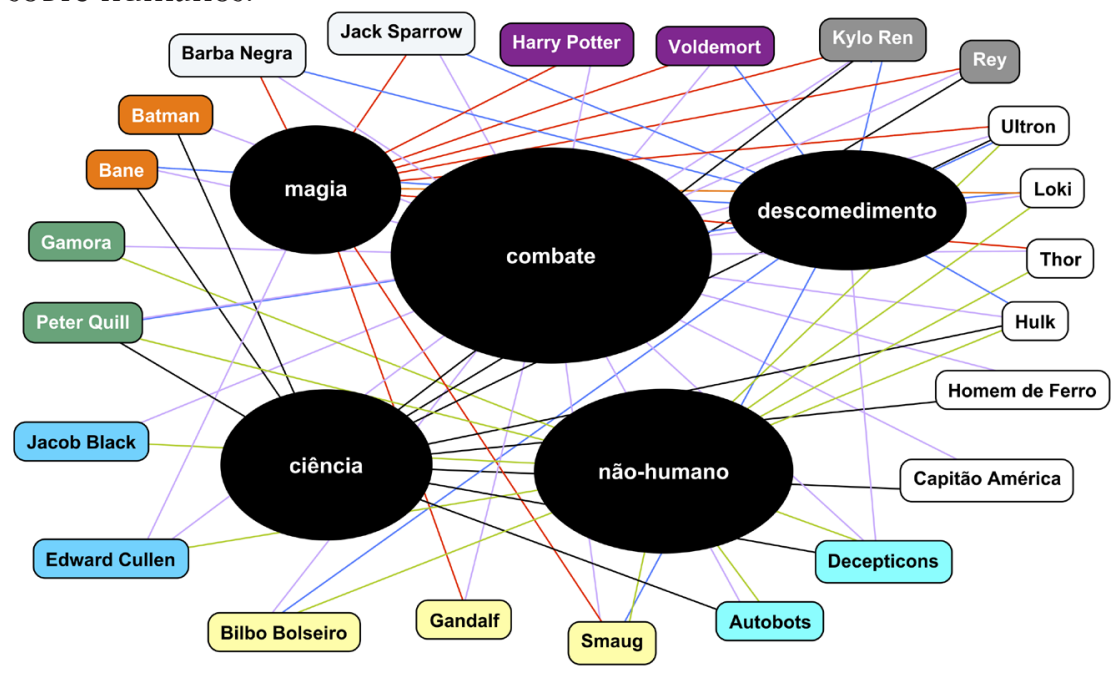

Fonte: elaboração própria.

O mapeamento (Figura 2), que mostra as conexões entre os principais personagens sobre-humanos dos filmes analisados e os mitemas mais presentes nesses filmes, revela ainda que os personagens caracterizados como seres dotados de capacidades que vão além da natureza humana são representados como produto da ciência moderna, dotados 
de poderes mágicos e/ou como não humanos (alienígenas, robôs, mutantes etc.), conforme sintetizado na Tabela 4.

Tabela 4. Características do sobre-humano nos personagens.

\begin{tabular}{|c|c|c|c|c|}
\hline \multirow{2}{*}{$\begin{array}{l}\text { Universo } \\
\text { narrativo }\end{array}$} & \multirow[b]{2}{*}{ Personagem } & \multicolumn{3}{|c|}{$\begin{array}{l}\text { O que o caracteriza como sobre-humano } \\
\text { no universo narrativo }\end{array}$} \\
\hline & & $\begin{array}{l}\text { Uso da } \\
\text { ciência e } \\
\text { tecnologia }\end{array}$ & $\begin{array}{l}\text { Poderes } \\
\text { mágicos }\end{array}$ & $\begin{array}{l}\text { Nature- } \\
\text { za não } \\
\text { humana* }\end{array}$ \\
\hline \multirow{2}{*}{$\begin{array}{l}\text { O Cavaleiro das } \\
\text { Trevas }\end{array}$} & Batman & & & \\
\hline & Bane & & & \\
\hline \multirow{2}{*}{ Star Wars } & Rey & & & \\
\hline & Kylo Ren & & & \\
\hline \multirow{2}{*}{ Harry Potter } & Harry Potter & & & \\
\hline & Voldemort & & & \\
\hline \multirow{6}{*}{$\begin{array}{l}\text { Os Vingadores } \\
\text { (Marvel) }\end{array}$} & Homem de Ferro & & & \\
\hline & Capitão América & & & \\
\hline & Thor & & & \\
\hline & Hulk & & & \\
\hline & Loki & & & \\
\hline & Ultron & & & \\
\hline \multirow{2}{*}{ Transformers } & Autobots & & & \\
\hline & Decepticons & & & \\
\hline \multirow{3}{*}{ O Hobbit } & Bilbo Bolseiro & & & \\
\hline & Gandalf & & & \\
\hline & Smaug & & & \\
\hline \multirow{2}{*}{$\begin{array}{l}\text { Guardiões da } \\
\text { Galáxia }\end{array}$} & Peter Quill & & & \\
\hline & Gamora & & & \\
\hline \multirow{2}{*}{ Crepúsculo } & Edward Cullen & & & \\
\hline & Jacob Black & & & \\
\hline \multirow{2}{*}{$\begin{array}{l}\text { Piratas do } \\
\text { Caribe }\end{array}$} & Jack Sparrow & & & \\
\hline & Barba Negra & & & \\
\hline $\begin{array}{l}\text { Nascem como nã } \\
\text { humanas }\end{array}$ & humanos ou assun & em caracterí & s não & \\
\hline
\end{tabular}

Fonte: elaboração própria. 
Dessa forma, a combinação dos elementos simbólicos que se agrupam em torno do mitema da magia (mago, objeto mágico ou sagrado, místico, natureza, reintegração cósmica e visões), da ciência (cientista, tecnologia, arma especial, inteligência artificial) e a morte e a ressurreição, que se associam a ambos os temas, é o que define a capacidade sobre-humana de protagonistas e antagonistas nas narrativas, além, em alguns casos, da inserção de elementos propriamente não humanos (mutante, monstro, robô, alienígena e ser mítico).

O sobre-humano, em parte significativa desses imaginários, está, assim, intimamente ligado a elementos simbólicos que remetem à combinação de temas científico-tecnológicos e mágicos, temas que estão frequentemente no núcleo narrativo das produções audiovisuais de maior sucesso desde o início dos anos 2000.

É interessante notar que os temas científico-tecnológicos nas produções audiovisuais bem-sucedidas comercialmente têm extrapolado a ficção científica e alcançado diversos gêneros, entre eles as narrativas de ação e aventura, como nos filmes e séries sobre super-heróis ("Homem de Ferro", "Os Vingadores", "Batman”), os dramas médicos e policiais ("CSI", "House", "NCSI", "Grey's Anatomy"), a comédia ("The Big Bang Theory") e o horror ("The Walking Dead"), entre outros. Tal fenômeno é, paradoxalmente, acompanhado por um movimento oposto. Narrativas em que elementos simbólicos relacionados à magia e ao sobrenatural (fantástico) predominam em seus imaginários têm atingido praticamente a mesma popularidade, especialmente no cinema a partir dos anos 2000 (ANAZ, 2016, p. 94).

Tal fenômeno é o reflexo do compartilhamento bem-sucedido entre criadores e audiências de um imaginário em que o "reencantamento" do mundo passou a dividir espaço com o desencantamento da "verdade absoluta" científica (ANAZ, 2016, p. 103).

Além disso, o mitema do combate - com seus simbolismos de luz versus trevas, liberdade versus opressão, desertor, rebelde, vigilante e exilado - está associado a praticamente todos os personagens sobre-humanos e o do descomedimento - com seus elementos de corrupção, destruição 
em massa, extinção, totalitarismo, negociante, instituições/corporações -, predominantemente aos antagonistas (vilões).

Fruto das combinações desses mitemas, o arquétipo do sobre-humano na cinematografia contemporânea está relacionado principalmente com os arquétipos do herói, em suas diferentes variações - do herói vigilante na trilogia $O$ Cavaleiro das Trevas ao herói passivo na trilogia $O$ Hobbit; do mentor, como Gandalf (O Hobbit); e da sombra, como Loki (Os Vingadores), entre outros.

Essa redundância do sobre-humano pode ser um indicador empírico do interesse das audiências globais, nas últimas décadas, por narrativas que transcendem o histórico (particular e profano) e atingem um patamar mítico (universal e sagrado).

\section{A demanda contemporânea por universos míticos}

O significativo sucesso dos filmes de aventura e ação que combinam ficção científica e fantasia é um fenômeno dos anos 2000, mas suas raízes estão nas primeiras décadas da Era dos Blockbusters, que tem seu marco inicial com os sucessos de Tubarão (Steven Spielberg, 1975), Star Wars: Uma Nova Esperança (George Lucas, 1977), Encontros Imediatos do Terceiro Grau (Steven Spielberg, 1977) e Superman (Richard Donner, 1978).

Anaz (2016, p. 95) mostra que a década de 1980 consolida a ascensão dos temas associados à ciência moderna e à tecnologia, com metade dos títulos de maior sucesso tratando deles - como, por exemplo, ET, o Extraterrestre (Steven Spielberg, 1981), De Volta para o Futuro (Roberto Zemeckis, 1985) e Batman (Tim Burton, 1989). Nos anos 1990, 40\% dos filmes entre as maiores bilheterias anuais têm a magia como tema central de suas narrativas.

Assim, há um progressivo crescimento da participação dos elementos simbólicos associados à ciência e tecnologia e ao seu contrário, a magia, nos imaginários das narrativas de maior sucesso (Tabela 5). 
Tabela 5. Participação de temas relacionados a ciência e tecnologia e a magia no imaginário dos filmes com as maiores bilheterias entre as décadas de 1960 e 2010.

\begin{tabular}{llll}
\hline Década & $\begin{array}{l}\text { Ciência e } \\
\text { tecnologia }\end{array}$ & Magia & Total \\
\hline 1960 & $20 \%$ & 0 & $20 \%$ \\
1970 & $20 \%$ & $10 \%$ & $30 \%$ \\
1980 & $50 \%$ & $5 \%$ & $55 \%$ \\
1990 & $40 \%$ & $20 \%$ & $60 \%$ \\
2000 & $30 \%$ & $40 \%$ & $70 \%$ \\
$2011-2015$ & $65 \%$ & $15 \%$ & $80 \%$ \\
\hline
\end{tabular}

Fonte: Anaz (2016, p. 95).

$\mathrm{Na}$ fase que precede a Era dos Blockbusters, a da chamada "Nova Hollywood" ou "American New Wave", em que prevalece a ênfase no realismo, a liberdade criativa e a influência das ideias da contracultura, predominam, nos filmes com as maiores bilheterias mundiais, protagonistas e antagonistas mais realistas e sem capacidades sobre-humanas, como em O Poderoso Chefão (Francis Ford Coppola, 1972), Butch Cassidy e Sundance Kid (George Hill, 1969) e Quem tem Medo de Virgínia Wolf? (Mike Nichols, 1966), por exemplo.

Essa mudança aponta para a possibilidade de que o sobre-humano como tema central dos imaginários de uma das linhagens de filmes bem-sucedidos a partir dos anos 2000 seja um dos índices de um fenômeno mais amplo: o da construção de universos míticos contemporâneos, em um processo de atualização mitológica que teria no cinema um de seus principais vetores.

Não que a atualização dos mitos seja um fenômeno recente, nem que o cinema seja seu protagonista.

Durand, Jung, Eliade, Campbell e Armstrong são alguns dos pensadores que identificaram uma remitologização no seio da Era Moderna, paradoxalmente a que se propôs a mais desmitologizadora, com o predomínio dos paradigmas da ciência clássica, do positivismo, do funcionalismo e do materialismo histórico. Durand (2004), por exemplo, 
indica que, a partir da segunda metade do século XIX, no auge do positivismo, há uma reabilitação das imagens arquetípicas e míticas no cenário científico, filosófico e artístico, com as produções de Nietzsche, Richard Wagner, Émile Zola, Freud e Thomas Mann, entre outros.

O mito, discurso que racionaliza o imaginário, é parte integrante do processo de equilíbrio biopsicossocial do ser humano no mundo. Para lidar com as angústias existenciais da autoconsciência da morte e do tempo (DURAND, 2002) e dar valor e significado à vida (ARMSTRONG, 2005), o homo sapiens, a partir da revolução cognitiva ocorrida entre 70 mil e 45 mil anos atrás que lhe deu a capacidade de imaginar o que não existe (HARARI, 2015), desenvolve narrativas que dão sentido a sua existência e a das coisas no mundo, narrativas essas que se articulam em ordens imaginadas, como as mitologias.

Estudioso das religiões e uma das influências no pensamento de Durand, com quem participou do círculo de Eranos, ${ }^{13}$ Mircea Eliade (1907-1986) entende que o homem arcaico, aquele que imaginou os mitos fundadores, sente-se indissoluvelmente vinculado ao Cosmo e aos ritmos cósmicos e vive de acordo com modelos extra-humanos (de acordo com o real e a lei, com os modelos arquetípicos platônicos), enquanto o homem moderno tenta se vincular prioritariamente à visão científica da história (ELIADE, 1992a). Para o primeiro, o tempo é predominantemente cíclico, com a contínua repetição (eterno retorno) dos fatos e modos de agir modelares estabelecidos pelas entidades míticas; já para o segundo, ele é predominantemente linear e irreversível. "Predominantemente" porque, tanto para um quanto para o outro, a linearidade da história e o eterno retorno mítico estão presentes.

Assim, mesmo com o desencantamento/desmagificação do mundo (Max Weber) levado a cabo durante séculos pelas éticas religiosas monoteístas e pelo pensamento científico moderno - com suas consequências de perda do sentido religioso (de religação) da vida e da submissão

13 Ciclo de conferências iniciado em 1933 que reunia pensadores de várias áreas do conhecimento para reflexões interdisciplinares sobre os símbolos, o imaginário e o mito. Entre os participantes dos encontros de Eranos estavam Carl Jung, Mircea Eliade, Gilbert Durand, Henry Corbin, Joseph Campbell, Erwin Schrödinger, Heinrich Zimmer e Max Knoll, entre outros. 
humana à técnica (Martin Heidegger) -, o homem contemporâneo, para tolerar ou escapar do tempo histórico, busca religar-se ao tempo mítico e ao mito. Alguns fenômenos comunicacionais de massa, como as franquias cinematográficas de sucesso aqui analisadas, trazem índices de uma remitologização ou atualização mitológica que permeia a cultura dessacralizada contemporânea, sendo, como aqui observado, o sobre-humano um elemento simbólico central e comum a todas elas.

Para Soares (2010, p. 31),

o homem moderno, por mais dessacralizado que se pretenda, não consegue se ver livre da experiência mítica originária, ainda que ela ressoe, nos dias atuais $[. .$.$] , não mais como voz direta dos deuses, e sim como ecos$ oblíquos da própria psique humana ancestral.

Boa parte dos produtos de sucesso na cultura popular traz índices da necessidade do homem contemporâneo pelo mito - a mesma necessidade que havia em seus antepassados -, sendo o cinema uma das fontes para satisfazê-la. Pode-se pensar, assim, que as narrativas (cinematográficas e outras, ficcionais ou não ficcionais) operam em dois planos:

- no plano histórico, mais imediato, no âmbito do ego e superego societal, em que o tempo é profano - contínuo, linear e irreversível - e a representação dos fenômenos é particular; e

- no plano mítico, mais remoto, no âmbito do inconsciente antropológico, em que o tempo é sagrado - cíclico/eterno retorno - e a representação dos fenômenos é universal.

Várias narrativas na produção cinematográfica contemporânea parecem almejar o plano mítico em função desse operar a partir da ideia de arquétipos (Jung) e estabelecer uma universalidade para a história - o que resulta em processos de identificação cultural com a audiência que superam fronteiras geográficas e étnicas e tornam-se, assim, fator importante para o sucesso comercial da obra. Esse fenômeno pode ser observado inclusive em narrativas não ficcionais.

De forma geral, o plano mítico pode ser comparado ao da poética em Aristóteles, para quem a História se limita a mostrar o que aconteceu, 
enquanto a poesia mostra o que poderia acontecer, tornando a poética mais filosófica e virtuosa que a História (ARISTÓTELES, 2008, p. 54).

Figura 3. Esquema básico das fontes de conteúdo nas narrativas.

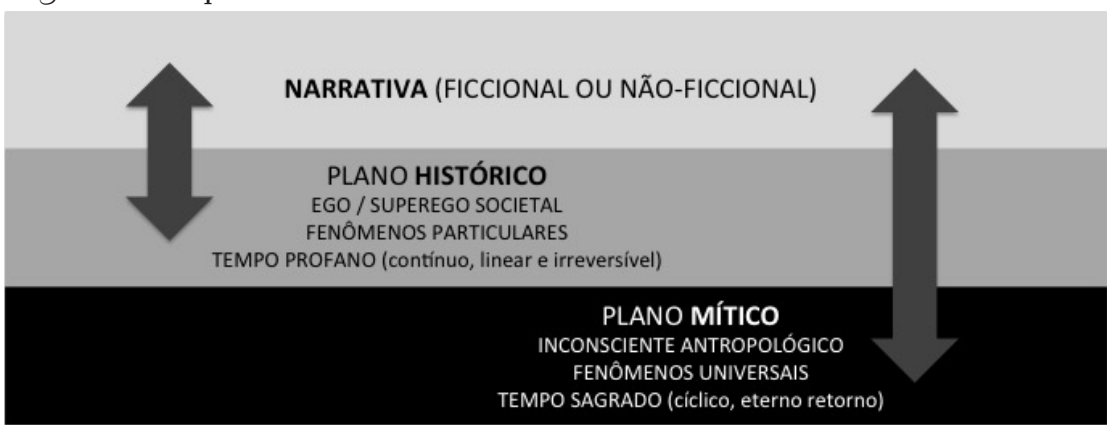

Fonte: elaboração própria.

Do ponto de vista da audiência, a demanda por narrativas que enfatizem o mítico pode ser o resultado de uma combinação: da busca, pelo ser humano, de um equilíbrio biopsicossocial - em função da angústia da autoconsciência da morte e do tempo; da urgência em dar sentidos à vida e estabelecer ligações com as origens do ser humano no planeta e com o macrocosmo em que se está inserido; e da tentativa de se escapar do "terror da História" (ELIADE, 1992a).

Nas últimas décadas, o cinema tem atendido parte dessa demanda com filmes que atualizam os mitos fundadores em novos universos míticos, nos quais o sobre-humano se destaca como elementos simbólico central, ainda que com diferentes qualidades.

\section{Conclusões}

$\mathrm{Na}$ primeira parte da investigação, foi possível identificar que os filmes que combinam ação, aventura e ficção científica e/ou fantasia predominaram no gosto popular no âmbito global entre 2001 e 2015.

Ressalte-se, mais uma vez, que o sucesso desses filmes não é fruto unicamente do imaginário que constroem e compartilham, mas também 
de fatores como as estratégias de marketing e distribuição adotadas, a notoriedade do elenco e o uso de efeitos visuais, entre outros.

Ponderado esse aspecto, neste estudo, a análise mitocrítica centrou-se em uma amostragem representativa desses filmes bem-sucedidos comercialmente e revelou que os elementos simbólicos mais redundantes neles convergem para cinco mitemas: do combate, do não humano, da magia, do descomedimento e da ciência.

Os mitemas, por sua vez, convergem para um elemento simbólico comum a todas as narrativas analisadas: o arquétipo do sobre-humano, definido, de forma ampla, como um ser dotado de capacidades (científico-tecnológicas e/ou mágico-sobrenaturais e/ou morfológicas) que vão além das da natureza humana. Assim, as representações do sobre-humano nos filmes analisados aparecem como produto da ciência moderna, dotados de poderes mágicos e/ou como algo de natureza não humana.

$\mathrm{Na}$ hipótese aqui desenvolvida, a redundância da imagem arquetípica do sobre-humano se torna um indicador empírico de uma demanda (ou de uma adesão) das audiências por temas que extrapolem o realismo e a história e estejam inseridos em universos míticos.

Tal fenômeno pode indicar um movimento de atualização mitológica (remitologização ou reencantamento) em curso nos imaginários da sociedade contemporânea. Assim, é possível que os imaginários compartilhados pelas narrativas do cinema mainstream busquem responder à demanda pelo equilíbrio biopsicossocial do ser no mundo (Durand) e, também, sejam tentativas do homem de escapar do reducionismo historicista (Eliade) a que está sujeito no mundo moderno.

A mitocrítica também indicou que a demanda, no âmbito da audiência, por narrativas que acionam o plano mítico tem sido atendida por produções cinematográficas (criação) que atrelam ao arquétipo do sobre-humano duas lições míticas essenciais:

- da punição do descomedimento (hybris), através da ação de um ser que está (ou se coloca) acima de um mundo corrompido; e

- do triunfo, na disputa entre forças opostas, da ação que (re)conduz ao equilíbrio e à harmonia do Cosmo. 
Se tomarmos como referência a classificação dos regimes de imagens proposta por Durand (2002) - em que as imagens que compõem um imaginário são diurnas (heroicas) ou noturnas (dramáticas ou antifrásicas) -, as lições míticas (punir e triunfar) indicam que a imagem arquetípica do sobre-humano nas narrativas analisadas está ligada principalmente aos mitos apolíneos e prometeicos e é preenchida por imagens diurnas, que são regidas pela lógica do combate, da purificação, da separação e da elevação.

Tais resultados, que apontam para a adesão de grande parte das audiências globais às lições míticas aqui identificadas, não significam necessariamente que essas narrativas operem, à semelhança dos mitos fundadores, como proponentes de modelos de conduta na sociedade contemporânea. Para se verificar se tal fenômeno ocorre, os achados desta investigação devem ser vistos apenas como um ponto de partida para futuros estudos que investiguem o impacto dessas narrativas e do imaginário que compartilham na perspectiva da recepção.

Outra conclusão possível no âmbito desta investigação é que, para alcançar a universalidade de seus elementos simbólicos a partir do plano narrativo mítico, a produção cinematográfica bem-sucedida entre 2001 e 2015 aqui analisada (filmes que mesclam aventura, ação, ficção científica e/ou fantasia) explora predominantemente um dos eixos narrativos e de representação (diurno/heroico) no âmbito do imaginário, resultando em temas e personagens homogeneizantes, sem explorar plenamente o potencial arquetípico dos personagens, inclusive o do sobre-humano.

O plano narrativo mítico oferece possibilidades de construção de personagens e temas mais complexos a partir de um equilíbrio no uso dos três eixos de representação. Apesar de algumas das narrativas analisadas explorarem, em alguns momentos, imagens alinhadas aos eixos noturno/místico e noturno/dramático, regidos pelas lógicas do repouso, do equilíbrio, da harmonia e de integração diacrônica entre o heroico (separação) e o místico (mistura), elas o fazem de forma tímida.

Para dar um salto qualitativo em termos do imaginário que compartilha, o desafio para essa combinação bem-sucedida de gêneros está em 
criar filmes com representações heterogeneizantes que desenvolvam plenamente as possibilidades que os arquétipos e os mitos oferecem às narrativas.

\section{Referências}

ANAZ, S. Do sucesso à subversão do imaginário científico-tecnológico em filmes e séries. Revista Comunicação Midiática, v. 11, n. 3, p. 90-104, set.-dez. 2016.

ARISTÓTELES. Poética. Lisboa: Calouste Gulbekian, 2008.

ARMSTRONG, K. Breve História do Mito. São Paulo: Companhia das Letras, 2005.

BENJAMIN, W. Textos Escolhidos. São Paulo: Abril Cultural, 1975. (Coleção Os Pensadores).

DURAND, G. As Estruturas Antropológicas do Imaginário. São Paulo: Martins Fontes, 2002.

. O retorno do mito. Introdução à mitologia. Mitos e sociedade. Revista FAMECOS, v. 11, n. 23, p. 7-22, 2004.

. Passo a passo mitocrítico. Revista Ao Pé da Letra, v. 14, n. 2, p. 129-147, 2012.

. Sobre a exploração do imaginário, seu vocabulário, método e aplicações transdisciplinares. Revista da Faculdade de Educação, v. 11, n. 1-2, p. 243-273, 1985.

ELIADE, M. Mito do Eterno Retorno. São Paulo: Mercuryo, 1992a.

. O Sagrado e o Profano. São Paulo: Martins Fontes, 1992b.

HARARI, Y. H. Sapiens: uma breve história da humanidade. São Paulo: LP\&M, 2015.

JOSHI, A.; MAO, H. Adapting to succeed? Leveraging the brand equity of best sellers to succeed at the box office. Journal of the Academy of Marketing Science, v. 40, n. 4, p. 558-571, 2012.

MARTEL, F. Mainstream: a guerra global das mídias e das culturas. Rio de Janeiro: Civilização Brasileira, 2012.

MORIN, E. Ciência com Consciência. Rio de Janeiro: Bertrand Brasil, 2005.

MORRIS, M.; LI, S. L.; CHING-KIU, S. C. Hong Kong Connections: Transnational Imagination in Action Cinema. Durham: Duke University Press, 2006.

NOGUEIRA, L. Gêneros Cinematográficos. Covilhã: LabCom Books, 2010.

O'BRIEN, H. Action Movies: The Cinema of Striking Back. Nova York: Columbia University Press, 2012.

SEDGWICK, J.; POKORNY, M. An Economic History of Film. Londres: Routledge, 2004. 
SOARES, C. Evangelhos da Revolta: Camus, Sartre e a remitologização moderna. 2010. 290f. Tese (doutorado em Filosofia). Faculdade de Filosofia, Letras e Ciências Humanas, Universidade de São Paulo, São Paulo, 2010.

\section{Sobre 0 autor}

Sílvio Antonio Luiz Anaz - Doutor em Comunicação e Semiótica pela Pontifícia Universidade Católica de São Paulo. Pós-doutorando em Meios e Processos Audiovisuais na Escola de Comunicações e Artes da Universidade de São Paulo (bolsista Fapesp).

Data de submissão: 02/01/2017

Data de aceite: $21 / 11 / 2017$ 